\title{
Results in Neurodevelopment after Open Cardiac Surgery in Pediatric Patients
}

\author{
Adriana Nieto-Sanjuanero*, Arturo Alejandro García-Ramírez, Ramón Gerardo Sánchez-Cortés, \\ Joshua Rodrigo De la O-Vega, Arturo Gerardo Garza-Alatorre and Manuel Enrique De la O-Cavazos
}

Department of Pediatrics, School of Medicine and University Hospital "Dr. José Eleuterio Gonzaléz", Universidad Autónoma de Nuevo León (U.A.N.L.), México

*Corresponding author: Adriana Nieto-Sanjuanero, MD, Department of Pediatrics, School of Medicine and University Hospital "Dr. José Eleuterio González", Universidad Autónoma de Nuevo León (U.A.N.L.), Av. Francisco I. Madero, s/n, Col. Mitras Centro, C.P. 66460, Monterrey, Nuevo León, México



\begin{abstract}
Introduction: Heart diseases are considered among the most frequent congenital malformations; they have a great impact on pediatric morbidity and mortality. Children with congenital heart disease present motor and neurocognitive deficits, as well as specific functions such as attention and executive functions can be affected.
\end{abstract}

Materials and methods: It is an observational, analytical, retrospective, and cohort study, in which 10 postoperative cardiac surgery patients with the use of an extracorporeal pump were recruited regardless of the structural cardiac alteration they presented.

Results: Using BSID-III, the neurodevelopment of the patients was evaluated. These results are shown in Table 1 and Table 2 with composite scores, as well as developmental subscales. The evaluations were carried out in the 3 main areas of development (Table 1), finding in the cognitive area a median of 97.5 with a minimum of 55 and a maximum of 110 with $70 \%$ in the normal range and $30 \%$ abnormal. The language area the median was 88.5 with a minimum of 53 and a maximum of 106 , with a normality of $60 \%$ or $40 \%$ abnormal, while in the global motor area a median of 85 was obtained with a minimum of 46 and a maximum of 107 with $50 \%$ normal and $50 \%$ abnormal.

Conclusions: It was shown that despite the test being performed at an average age of 8 months, $50 \%$ of the patients presented deterioration in neurodevelopment. It has been shown that the Bayley Child Development Scale is widely recommended as a test in the assessment of neurodevelopment, however it is not the only one that can be performed. It is important to follow up the patients at later ages since the alterations in the executive functions will be reflected and this will bring more evident alterations to learning in the school stage.

\section{Keywords}

Cardiac surgery, Heart disease, Neurodevelopment, Pediatrics

\section{Introduction}

Heart disease is considered one of the most frequent congenital malformations and has a great impact on pediatric morbidity and mortality. For the present work, we used as the definition of congenital heart disease that of Mitchell, et al., which speaks of an evident structural abnormality of the heart or of the large intrathoracic vessels with a real or potential repercussion [1].

The prevalence reported worldwide ranges from 2.1 to 12.3 per 1000 newborns. In our country, its real prevalence is unknown, as a cause of infant death, it is ranked sixth in children under one year of age and as the third cause in children between one and four-yearsold, based on the birth rate, it is estimates that around 10,000 to 12,000 children are born with some type of heart malformation [2].

Children with congenital heart disease present neurocognitive deficits that can be reflected not only in intelligence, specific functions such as attention and executive functions can be affected [3-5].

Other alterations that these patients present are attention deficit and hyperactivity disorders, this due to alterations in the development of the prefrontal cortex. Alterations such as dyslexia are conditions that are

Citation: Nieto-Sanjuanero A, García-Ramírez AA, Sánchez-Cortés RG, De la O-Vega JR, Garza-Alatorre AG, et al. (2019) Results in Neurodevelopment after Open Cardiac Surgery in Pediatric Patients. Int J Pediatr Res 6:068. doi.org/10.23937/2469-5769/1510068

Accepted: October 01, 2020: Published: October 03, 2020

Copyright: (c) 2020 Nieto-Sanjuanero A, et al. This is an open-access article distributed under the terms of the Creative Commons Attribution License, which permits unrestricted use, distribution, and reproduction in any medium, provided the original author and source are credited. 
Table 1: Results in neurodevelopment with BSID-III in the composite score in the three areas of development.

\begin{tabular}{|l|l|l|l|}
\hline \multicolumn{1}{|c|}{ Variable } & \multicolumn{3}{|c|}{$\mathbf{n = 1 0}$} \\
\hline $\begin{array}{l}\text { Composite } \\
\text { Score M }\end{array}$ & Median (range) & $\begin{array}{l}<\mathbf{8 5}(\%) \\
\mathbf{n ~ ( \% )}\end{array}$ & $\begin{array}{l}<\mathbf{8 5}(\%)^{\mathbf{1}} \\
\mathbf{n}(\%)\end{array}$ \\
\hline Cognitive & $97.5(55-110)^{2}$ & $3(30)^{3}$ & $7(70)$ \\
\hline Language & $88.5(53-106)$ & $4(40)$ & $6(60)$ \\
\hline Motor & $85(46-107)$ & $5(50)$ & $5(50)$ \\
\hline
\end{tabular}

1: Normal value of the composite score $\geq 85$; ${ }^{2}$ : These values correspond to median and range (minimum and maximum); 3 : These values are expressed as a proportion of the number of cases (percentage).

Table 2: Score of the Development Subscales with the BSIDIII.

\begin{tabular}{|l|l|l|l|}
\hline Development subscale & $\begin{array}{l}\text { Median } \\
\text { (range) }\end{array}$ & $\begin{array}{l}\mathbf{<} 8 \\
\mathbf{n}(\%)\end{array}$ & $\mathbf{n}(\mathbf{8})$ \\
\hline Cognitive (C) & $9(1-12)$ & $3(30)$ & $7(70)$ \\
\hline Responsive communication (RC) & $7(1-11)$ & $4(40)$ & $6(60)$ \\
\hline Expressive communication (EC) & $8.5(1-11)$ & $4(40)$ & $6(60)$ \\
\hline Fine motor (FM) & $8(1-9)$ & $4(40)$ & $6(60)$ \\
\hline Gross motor (GM) & $7(1-13)$ & $5(50)$ & $5(50)$ \\
\hline
\end{tabular}

1: Normal value of the subscale $\geq 8$.

diagnosed after the reading period, around 4-5 years, however, the structures necessary for reading can show dysfunction from earlier stages $[5,6]$.

The evolution of cognitive and psychomotor development in the group of patients undergoing extracorporeal cardiac surgery has been little studied, due to the variations in age at the time of surgery and the age of evaluation. Different study tools are necessary to determine developmental patterns in pediatric patients after cardiac surgery $[1,4]$.

Surgical and non-surgical variables have been related to a poor prognosis in the development of neurological disorders. Variables such as neurological alterations prior to surgery, structural injury, low birth weight, postoperative complications, the use of profound hypother$\mathrm{mia}$, as well as the long duration of circulatory arrest are some that should be taken into account when making a neurological evaluation in patients $[4,7]$.

The Bayley Scales of Infant Development, currently in its third edition (BSID-III), is internationally recognized as one of the most comprehensive tools for the assessment of infants. It is widely used in research, clinical practice, and intervention evaluation as it assesses motor, cognitive and language areas are also subdivided into subscales in motor area (gross and fine) and language (receptive and expressive) [8]. The scale can be administered flexibly by making accommodations and modifications so that the succession and speed of the items presented to the child are adapted to a combination of factors such as age, temperament, and the success of the relationship. This scale is also useful in clinical, educational and research settings $[8,9]$.

The hypothesis proposed in this study was that children undergoing cardiac surgery with extracorporeal pump present an evaluation of psychomotor development, measured by developmental scales corresponding to age, lower than that of the general population. The objective was to evaluate the neurodevelopmental outcome in those patients who underwent open heart surgery for congenital heart disease.

\section{Materials and Methods}

It is an observational, analytical, retrospective, and cohort study, in which 10 patients were recruited from the pediatric outpatient clinic of the Hospital Universitario "Dr. José Eleuterio González", after cardiac surgery with the use of an extracorporeal pump, regardless of cardiac structural alteration to present.

The selection criteria for this study included the following inclusion criteria: Pediatric patients undergoing extracorporeal cardiac surgery between 0 days of life and 48 months of life. The exclusion criteria were: Patients who present a genetic or chromosomal syndrome, patients who present malformation at the central nervous system level, premature patients $<36$ weeks of gestation by assessment using the Capurro or Ballard scales, patients who have presented a neurological event or who have required advanced resuscitation maneuvers at some point in their life. The elimination criteria included were those patients with an incomplete medical history, incomplete record, or who died before the final evaluation was performed.

The patients were recruited from the pediatric outpatient clinic, where post-operative cardiac surgery patients were followed up. BSID-III is included in the pediatric evaluation performed on these patients. BSIDIII was applied by trained personnel from the pediatric office 6 months after cardiac surgery. The results of this test were recorded in the patient's clinical record for later compilation.

The research protocol of this work was approved by the Research Ethics Committee on March 6, 2019, granting a registration number PE19-00005.

A descriptive analysis was performed with measures of central tendency and dispersion, and the normality of the data was evaluated using the Komolgorov-Smirnov test. The Bayley III child development scale tests were evaluated using medians, as well as ranges and percentage for proportion of numbers of cases. The statistical analysis was performed using version 24 of the Statistical Package for Social Sciences (IBM SPSS Statistics Version 24, IBM Corporation 2015).

\section{Results}

Information was collected from a total of 10 patients 
Table 3: Demographic and morbidity variables prior to surgery.

\begin{tabular}{|l|l|}
\hline Variable & Total $(\mathbf{n}=\mathbf{1 0})$ \\
\hline Gender $(\mathrm{n}$, male) & $5 / 10^{*}$ \\
\hline Weight $(\mathrm{Kg})$ & $2.9(2-7.5)^{* *}$ \\
\hline Age (months) & $2(0.3-17)$ \\
\hline Pre-surgical ventilation & $2 / 10$ \\
\hline Pre-surgical shock & $2 / 10$ \\
\hline Diagnosis & $1 / 10$ \\
\hline Pulmonary atresia + IAC & $1 / 10$ \\
\hline AV canal + Ao hypoplasia & $1 / 10$ \\
\hline Incomplete AV canal + IAC + single atrium & $1 / 10$ \\
\hline TGV + DORV + IVC + IAC + hypoplasia Ao & $1 / 10$ \\
\hline IVC + IAC & $2 / 10$ \\
\hline TGV & $2 / 10$ \\
\hline
\end{tabular}

*: These values are expressed in proportion (number of cases/ total sample); ${ }^{* *}$ : These values correspond to median and range (minimum and maximum).

who met the inclusion and exclusion criteria, all of them underwent an assessment through the BSID-III which was 6 months after the surgical procedure.

Of the total sample, 5 patients were male and $5 \mathrm{fe}$ male with a median age of 2 months in a minimum age range of 0.3 to a maximum of 17 months; mean weight at the time of surgery was $2.9 \mathrm{~kg}$ (minimum $2 \mathrm{~kg}$ and maximum $7.5 \mathrm{~kg}$ ). Two patients out of the ten recruited required mechanical ventilation prior to the surgical event and these patients also presented a state of shock prior to the surgical procedure. Likewise, the different heart diseases presented by the study patients were analyzed. Great heterogeneity of heart disease was found, with atrial and ventricular septum defects the most common, as well as transposition of the great vessels, with $4 / 10$ patients with atrial septal defect, $3 / 10$ patients with ventricular septal defect, and $2 / 10$ patients with transposition of the great vessels. Likewise, there were $3 / 10$ patients with complex heart disease with univentricular physiology. Pre-surgical and hospital stay variables were also obtained, which are shown in Table 3.

Regarding the surgery, the mean extracorporeal pump time in the patients was $152 \pm 110.4$ minutes and with a mean aortic clamping time of $87.2 \pm 57$ minutes. The 10 patients in the study presented postsurgical heart failure and one of them underwent ECMO therapy which remained for 72 hours under this therapy modality, did not have a shock state phase due to ECMO and had selective cerebral perfusion, so later came off ECMO therapy without complications. Three out of ten patients had the need for surgical reintervention due to the residual lesion they presented. In the pediatric intensive care area, an inotropic score was performed on the patients, which was $11.56 \pm 8.4$ points.

The patients who underwent the surgical procedure spent an average of $7.4 \pm 7.3$ days under mechanical
Table 4: Surgical variables and hospital stay.

\begin{tabular}{|l|l|}
\hline Variable & Results \\
\hline Pump time (minutes) & $152 \pm 110.4$ \\
\hline Aortic clamping time (minutes) & $87.2 \pm 57$ \\
\hline Post-surgical heart failure & $10 / 10^{* *}$ \\
\hline Reoperation for residual injury (n) & $3 / 10$ \\
\hline Post-surgical inotropic score & $11.56 \pm 8.4$ \\
\hline ECMO-VA & $1 / 10$ \\
\hline Days of mechanical ventilation & $7.4 \pm 7.3$ \\
\hline Days of stay in PICU & $15.6 \pm 11.6$ \\
\hline Days of hospital stay & $40.1 \pm 12.2$ \\
\hline
\end{tabular}

"*: These values are expressed in proportion (number of cases / total of the sample).

ventilation, with a length of stay in the pediatric intensive care area of $15.6 \pm 11.6$ days and a total hospital stay of $40.1 \pm 12.2$ days (Table 4 ).

Using BSID-III, the neurodevelopment of the patients was evaluated. These results are shown in Table 1 and Table 2 with composite scores, as well as developmental subscales. The evaluations were carried out in the 3 main areas of development (Table 1), finding in the cognitive area a median of 97.5 with a minimum of 55 and a maximum of 110 with $70 \%$ in the normal range and $30 \%$ abnormal. The language area the median was 88.5 with a minimum of 53 and a maximum of 106 , with a normality of $60 \%$ or $40 \%$ abnormal, while in the global motor area a median of 85 was obtained with a minimum of 46 and a maximum of 107 with $50 \%$ normal and $50 \%$ abnormal.

In the same way, evaluations were made in the developmental subscales (Table 2 ), finding the cognitive area a median of 9 with a minimum of 1 and a maximum of 12 with $70 \%$ normal and $30 \%$ abnormal. In the area of receptive communication, they had a median of with a minimum of 1 and a maximum of 11 with $60 \%$ normal and 40\% abnormal. Expressive communication had a median of 8.5 with a minimum value of 1 and a maximum of 11 with $60 \%$ normality and $40 \%$ abnormal. In the motor evaluations, the fine motor area was evaluated, where a median of 8 was obtained with a minimum value of 1 and a maximum of 9 with $60 \%$ normal and $40 \%$ abnormal. The gross motor area had a median of 7 with a minimum of 1 and a maximum of 13) with $50 \%$ normal.

\section{Discussion}

The study was able to demonstrate that patients with congenital heart disease who underwent cardiac surgery had neurodevelopmental alterations within a period of 6 months during which the evaluation was performed.

Three of the ten patients presented global neurodevelopmental alteration, a statistic similar to studies pre- 
viously carried out by Sananes 2012 in which, through evaluation with BSID-III, it was shown that $30 \%$ of their sample had neurological development alteration.

Bellinger 1999, 2006 presented various neurodevelopmental studies in patients with different congenital heart diseases, in which they determined that by evaluating the Peabody motor development scale, patients from an early age presented alterations. In patients with transposition of the great vessels, $37 \%$ of the patients had motor alterations. In our study, 3 patients had heart disease that presented in the form of transposition of the great vessels, 1 out of 3 of the patients presented motor alterations in the gross motor area.

The different areas of neurodevelopment were analyzed. It was found that alterations in motor development were presented more frequently compared to cognitive and language development, which, although they were also affected, not in the same proportion.

In the Starken 2015 study, which consisted of a meta-analysis with a total sample of 700 patients, it was shown that patients not only had cognitive alterations, but also that motor and visuospatial alterations are affected in $10 \%$ of patients purchased against a healthy control group with a significant $p<0.001$.

In these patients with motor impairment, abnormalities in the gross motor subscale were found in $50 \%$ of the patients. Fine motor alterations were affected in $40 \%$, thus reflecting that more than half of the patients in the studies had motor alterations.

In the language area, $40 \%$ of the patients presented alterations, of which proportional alterations were seen in the different types of communication evaluated, which are receptive communication and expressive communication with 4 patients each.

Both in the study carried out by Sananes and Starken, the patients presented alterations in both expressive and receptive language. They indicate that a third of the patients present language alterations and that this in the future has been related to an alteration in executive functions.

Cognitive alterations occurred in $30 \%$ of the patients, this may be due to the age at which the evaluation was carried out, since the mean age of the evaluation was 8 months of age \pm 11.3 months.

Among the weaknesses of this study, it can be mentioned that currently in our country there are no reports on psychomotor development in this group of patients and it was not possible to have the support of literature within our geographical area, for this reason it was important to carry out this investigation. It is of utmost importance to recognize the developmental delay data as early as possible in order to provide our patients with timely rehabilitation therapy according to the affected area.

\section{Conclusions}

There are few studies that evaluate neurodevelopment in these patients in our country, most of the previous studies are carried out in tertiary centers in which the conditions of hospitals, as well as access to various drugs and intensive therapies allow patients have a better chance of development.

It was shown that despite the test being carried out at an average age of 8 months, $50 \%$ of the patients presented deterioration in neurodevelopment, while the remaining $50 \%$ had normal development, of the evaluated patients it was observed that the most commonly affected area in order of frequency was: Motor (the gross motor subscale was the one that was most affected), language and cognitive. The bibliography indicates that motor alterations are the ones that are usually affected in the first instance, because they are the first in development at an early age while language develops later, so their assessment at an early age is not very accuratein many of the cases if the corresponding tests are not applied.

It has been shown that BSID-III is widely recommended as a test in the assessment of neurodevelopment; however it is not the only one that can be performed. The ideal would be to have an evaluation before and after surgery, so it is important to follow up patients at a later age since the alterations in executive functions will be reflected and this will bring learning alterations with greater clarity in the school stage.

In patients who were found with alterations, they were sent to a rehabilitation center for early stimulation therapy to acquire in a timely manner the developmental milestones in which they were delayed. This is the importance of early evaluation in patients already it allows them to improve in a timely manner in deficient areas with appropriate therapy.

\section{References}

1. Gaynor JW, Stopp C, Wypij D, Andropoulos DB, Atallah J, et al. (2015) Neuro developmental outcomes after cardiac surgery in infancy. Pediatrics 135: 816-825.

2. Balakrishnan PL, Juraszek AL (2012) Pathology of congenital heart disease. Neoreviews 13: e703-e710.

3. Polat S, Okuyaz C, Hallioğlu O, Mert E, Makharoblidze K (2011) Evaluation of growth and neurodevelopment in children with congenital heart disease. Pediatr Int 53: 345-349.

4. Sananes R, Manlhiot C, Kelly E, Hornberger LK, Williams WG, et al. (2012) Neurodevelopmental outcomes after open heart operations before 3 months of age. Ann Thorac Surg 93: 1577-1583.

5. Mussatto KA, Hoffmann RG, Hoffman GM, Tweddell JS, Bear L, et al. (2014) Risk and prevalence of developmental delay in young children with congenital heart disease. Pediatrics 133: e570-e577.

6. Acton BV, Biggs WSG, Creighton DE, Penner KAH, Switzer $\mathrm{HN}$, et al. (2011) Overestimating neurodevelopment using the Bayley-III after early complex cardiac surgery. Pediatrics 128: e794-e800. 
7. Dellinger RP, Levy MM, Carlet JM, Bion J, Parker MM, et al. (2008) Surviving Sepsis Campaign: international guidelines for management of severe sepsis and septic shock: 2008. Intensive Care Med 34: 17-60.

8. Madaschi V, Mecca TP, Macedo EC, Paula CS (2016) Bayley-III scales of infant and toddler development: Transcul- tural adaptation and psychometric properties. Paideia 26: 189-197.

9. Hallioglu O, Gurer G, Bozlu G, Karpuz D, Makharoblidze K, et al. (2015) Evaluation of neurodevelopment using Bayley-III in children with cyanotic or hemodynamically impaired congenital heart disease. Congenit Heart Dis 10: 537-541. 